\title{
Making research central to good paediatric practice
}

\author{
Hugh T Davies, ${ }^{1}$ Bob Phillips, ${ }^{02,3}$ Jennifer Preston, ${ }^{4}$ Simon R Stones ${ }^{5}$
}

- Additional material is published online only. To view please visit the journal online (http://dx.doi.org/10.1136/ archdischild-2018-315117).

${ }^{1}$ Health Research Authority, London, UK

${ }^{2}$ Department of Paediatric Oncology, Leeds Children's Hospital, Leeds, UK

${ }^{3}$ Centre for Reviews and Dissemination, University of York, York, UK

${ }^{4}$ NIHR Alder Hey Clinical Research Facility, Alder Hey Children's NHS Foundation Trust, Liverpool, UK

${ }^{5}$ School of Healthcare, University of Leeds, Leeds, UK

\section{Correspondence to}

Dr Bob Phillips, Centre for Reviews and Dissemination, University of York, York Y010 5DD, UK;

bob.phillips@doctors.org.uk

Received 22 August 2018 Revised 29 November 2018 Accepted 15 December 2018 Published Online First 22 March 2019

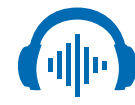

Listen to Podcast adc.bmj.com

Check for updates

(C) Author(s) (or their employer(s)) 2019. No commercial re-use. See rights and permissions. Published by BMJ.

To cite: Davies HT, Phillips B, Preston J, et al. Arch Dis Child 2019;104:385-388.

\section{ABSTRACT}

There is evidence abroad of a cautious if not protective approach to research involving children and young people (CYP). We are sensitive to these views but believe they are based on a misconception that we must address together. In this introductory article we look at the complexities and risks of this research, how we must involving CYP and their families in the all aspects of research, how to seek valid consent and assent and how research findings should be reported. Considering how we should conduct this ongoing debate, we outline seven principles that we believe should underpin the necessary dialogue between all with legitimate interest. Our debate should be: (1) evidence informed: arguments should be supported by appropriate and reasonably accurate factual claims; (2) transparent about the grounds for decisions; (3) balanced: arguments should be met by contrary arguments; (4) conscientious: we must be willing to talk and listen, with civility and respect; (5) substantive: arguments should be considered sincerely on their merits, not on how they are made or by who is making them; (6) comprehensive: all points of view held by significant portions of the population should receive attention; and (7) with procedures for revising decisions in light of challenges, and it should be our responsibility to ensure we have met all of these.

\section{INTRODUCTION}

As a reader of the Archives of Diseases in Childhood, you will most probably believe that research on the healthcare of neonates, children and young people (CYP) is a good thing. That it is practical to undertake, can be done ethically, effectively, and make meaningful differences to the well-being and survival of CYP with a range of disorders. There are some people who hold different views though. They are concerned and protective. It is not uncommon for people to be horrified of the idea of research being conducted 'on' CYP, without a clear understanding of the nature of what clinical research is, or entails. Examples of malfeasance receive prominent coverage to support this position. As evidenced in a recent survey, $58 \%$ of those asked thought CYP were not allowed to take part in research ${ }^{1}$ and even in early 2018, a major UK Children's Hospital received a horrified phone complaint from a member of the public who had learnt they were 'experimenting on children'. The hospital was engaged in a large number of perfectly valid, ethical, approved clinical trials. Beyond this, pragmatic issues present a barrier to research. There are healthcare providers who believe research is valid and useful, but not practical or possible in their setting. Even those engaged in research may be restricting access based on their mistaken beliefs around protecting families. ${ }^{2}$ We understand and are sensitive to these views but believe they are based on a misconception that fails to recognise the dual vulnerability of CYP-to possible research harm, yes, but more widely and more commonly with much consequent harm, to unresearched care. How do we present our case to such audiences? This first article in our series offers an insight into some of the complexities of undertaking research with CYP, how we can move forward and how we can work together to ensure a better understanding of the need to involve CYP in health research.

\section{COMPLEXITIES OF INVOLVING CYP IN RESEARCH}

The argument for involving CYP in research can be found all around us. The thirst for answers to the broad common questions of 'How do I diagnose this?‘, 'How do I treat this?', 'What caused this?' and 'What is the likely outcome of this?' echoes nearly every month in the Archimedes section of this journal. ${ }^{3}$ These questions outline the first pair of our beliefs: Care not informed by good quality evidence can be dangerous; though good quality evidence that is not implemented into practice is wasteful and can be just as dangerous. Poor quality research can harm CYP for years after publication, ${ }^{4}$ and it is obvious poor quality research is a risk to whomever it is undertaken on.

\section{Exploring risks and differences}

The first step is to explore this double vulnerability of CYP in research: we need to find the balance between the risks of research against the risks of care based on treatment which have not been subject to research. Studies which seek to trial new approaches which are genuinely felt to offer benefits may, in testing, fail to provide a better treatment than the ones which exist. Exposing CYP, particularly those with ill health to this risk could be considered unfair and unethical. However, the competing risk of not advancing therapies, or by acting on 'best guess' and pathophysiology, may produce the same results as the prone sleeping advice of previous decades. ${ }^{5}$

Historically, a solution used to address this risk is to test new drugs and interventions in adults, rather than CYP, before modifying the doses for CYP on the basis of understanding the pharmacology. However, this implies that the only thing that differs between CYP and adults is drug handling. While this is sometimes the case, it is not always; an apparently similar condition, such as acute lymphoblastic leukaemia, may have hugely different pathological mechanisms in a 3 month-old, 2 year-old, 15 year-old and 50 year-old. ${ }^{6}$ This example reinforces the necessity to consider undertaking research with CYP. 
Historical events can sometimes add to the difficulties faced. There have been mistakes and malpractice in research involving CYP, including the retention of organs without consent, ${ }^{7}$ and inaccurate reporting which has caused unnecessary suspicion. ${ }^{8}$ While we cannot change the course of history or the views of the entire population, we can make sure we own up to these mistakes and commit to research integrity, and that we seek every chance to explain the need for CYP's research and what it actually means.

\section{Gaining informed consent and assent}

Even if a need for CYP's research is accepted and is deemed safe, there may be anxieties around CYP being unable to give informed consent. However, this can and should be considered in the same way any other medical procedure would be undertaken in standard clinical care; consent should be sought from a legal guardian who acts in the best interests of CYP to make a considered decision about the choices offered, for example, parents and carers. A neonate cannot consent to surgery for volvulus, nor can an infant with retinoblastoma for radiotherapy, but both occur ethically. The same challenges are present in adults who do not have the capacity to consent for themselves, but this group too deserves access to appropriate research studies. The process of gaining informed consent needs to be age and developmentally appropriate, and assent should at least be sought from CYP who are able to communicate with adult professionals, in addition to consent from the legal guardian. Where viable, it is essential that CYP have a say in whether or not they wish to take part in research-a voice which cannot be ignored. In addition, gaining informed consent and assent should not be viewed as a solitary event; rather, it should be viewed as a continuous process involving mutual discussion and observations of both verbal and non-verbal signs of satisfaction with the research.

\section{Involving CYP and their families in the design of research}

Beyond including CYP as participants in research, the studies themselves need to have been designed from the earliest opportunity with CYP living with the condition, as well as their families in a patient and public involvement and engagement (PPIE) capacity, complementing the other relevant stakeholders involved in the design and conduct of the research. The views of what is the problem, what is acceptable to be treated with and how to undertake and evaluate research may differ markedly between researchers and CYP and their families; therefore, it is fundamental that everyone is involved meaningfully in the research process. ${ }^{9}$ How to make engagement meaningful, more than the 'tick box' experiences of some families from the past, we describe in forthcoming papers.

\section{Transparent reporting of research findings}

Beyond undertaking good quality research, the community needs to share it effectively and honestly-to both professional and public audiences. There is a wealth of literature published about the dangers of not reporting research findings. ${ }^{10} 11$ If research is not reported, we cannot get a fair and representative view of what the true answers to clinical questions are. As a consequence, we are left unsure, meaning that trials may be unnecessarily conducted with an ineffective intervention given to participants-or worse, skewed by selective publications, pouring resources and exposing patients to an intervention which does not work as well as we believe.

Even if research is reported, it needs to be reported clearly. This allows a fair assessment of the risks of biases to be made, and so an appreciation of its possible value in practice. Using an agreed structured report format ensures that the research which is undertaken is described clearly with all the key elements. These guides have been developed for a large number of study designs answering different clinical questions and are collected on the Enhancing the Quality and Transparency of Health Research Network website. ${ }^{12}$ A very well-known type of reporting guideline is the Consolidated Standards of Reporting Trials checklist; this sets out a minimum standard and list of items which need to be included in the reports of randomised clinical trials. Similar guidelines exist for systematic reviews (Preferred Reporting Items for Systematic Reviews and Meta-Analyses), observational studies (Strengthening the Reporting of Observational Studies in Epidemiology) and even animal preclinical studies (Animal Research: Reporting of In Vivo Experiments). If the ethical imperative does not encourage individuals to adhere to these reporting guidelines, the mandating of the correct approach being followed by major journals, including the $A D C$, ultimately may force individuals into doing the right thing anyways.

Traditional reporting of research in journals is barely adequate for dissemination of findings to academic professionals, but remain necessary for 'quality of research' assessments in higher education, for example, the UK Research Excellence Framework. ${ }^{13}$ Journal articles are largely inaccessible to the general public, even if research is published open access. The research community needs to engage with clinicians and the public in explaining and sharing its research. Public engagement, as part of a PPIE strategy, should be planned at the earliest opportunity of any given piece of research, if the community is to truly make research accessible for all. Vibrant approaches can be found in many places, for example, the picnics and portraits of the 'Born In Bradford' cohort study. ${ }^{14}$

\section{HOW THEN TO MOVE FORWARD?}

Research will only succeed if it is a true partnership involving those with legitimate interest. CYP (and all patients and public in general) should be active partners in research, with their views sought when relevant. Their involvement should map across the entire research process, including prioritisation, design, conduct and dissemination of research. As with other research methods, it should be a subject of research itself to determine its value and improve its contribution. We also need to actively recognise that clinical delivery of care may differ from the clinical researchers undertaking studies; this practical aspect of 'making research work for people' needs addressing. How then might we develop and conduct these partnerships successfully? This needs us to:

1. Identify all stakeholders with a legitimate interest.

2. Then engage with all stakeholders in fair debate.

CYP and families who have the health conditions under study will most likely share the professionals' view that research is of benefit. They are likely to be 'research friendly' and are often the champions of promoting research and the need for funding, encompassing the entire spectrum of prioritisation through to dissemination and further priority setting. The practicalities of how this can work will be explored further in a later paper, but in summary, include ongoing CYP research advocacy groups like Generation $\mathrm{R}^{15}$; specific prioritisation project groups, such as condition-relevant James Lind Alliance Priority Setting Partnerships ${ }^{16}$; and project-based groups like the BRIGHTLIGHT study Youth Advisory Panel. ${ }^{17}$

However, the emotional aspects of engaging and involving CYP and their families in research can be underestimated. Families, especially those whose CYP are currently in good health, are 
likely to more cautious in their approach, but there is support available. In a recent survey conducted by the Health Research Authority (HRA), $83 \%$ of members of the public said that health research is important. ${ }^{1}$ Focus group discussions have demonstrated that a major reason for caution is misunderstanding of the place and risks of research (HRA unpublished information). They are likely to share the view that research and care are separate activities, and should remain so.

To work with these concerns requires us to have an emotional understanding of research, while following some practical guidance. The UK has worked extensively in this area and can provide clear examples and guidance, such as through the National Institute for Health Research INVOLVE organisation, who provide further guidance on PPIE in research. Furthermore, a detailed report on the ethical elements to be considered with research can be enlightening. ${ }^{18}$

When research into research is examined, it is found clinical teams, while likely to voice statements supportive to the concept of research, can often find good reasons why it cannot be undertaken in their area or these particular cases. ${ }^{19}$ This may be a simple resource-stretch, emotional and mental overload of 'Too much to do...'; research is imperative but providing clinical care for CYP is more important.

Work from Professor Bridget Young at the University of Liverpool demonstrated that professionals are more of a barrier than patients. ${ }^{2}$ Despite saying little during trial discussions, parents described feeling comfortable and involved and they valued the way that practitioners explained the trials, but practitioners were often concerned that families were overwhelmed with information. When the parents were asked about this, they did not object to being asked about trials and many positively wanted to be approached.

Parents were more positive about being approached to enter their child into a clinical trial than practitioners anticipated. The concerns of some practitioners, that parents would be overburdened, were unfounded. Educating practitioners about how families perceive clinical trials and providing them with 'moral' support in approaching families may benefit paediatric research and, ultimately, patients.

Our inclusion of trials that recruited children who were severely or critically ill has confirmed that recruitment to such trials is more challenging for both parties. However, even in these circumstances, parents did not construe the trial approach as an unwelcome burden.

If you add to this some 'bad apple' stories of when the experience of healthcare professionals of research being unwieldy, impractical and unusable in the 'real world' of clinical practice along with ethical knots that may be tied ${ }^{20}$ there is a chunky barrier to overcome. It can be possible though-and there are several examples to demonstrate that it is practical. We would point to the example of children's haematology and oncology to show a specialty that was born with an integration of trials into everyday practice and continues to advance care through many different studies. ${ }^{21}$ This may be considered a golden bubble with the media, researchers and patients all with a heightened awareness of the need for research. Other parts of paediatrics have shown similar success though, with a range of huge neonatal trials undertaken across very large numbers of centres 2223 and the explosion of productive research networks, like Pediatric Emergency Research in the UK and Ireland in paediatric emergency care, which has demonstrated that emergency and acute paediatrics can be research active ${ }^{24}$ in the same fashion as their subspecialist or critical care cousins. Children's palliative and end of life care is not a research-free zone either, with research hubs producing work developing this. ${ }^{25}$

Research needs regulators and ethical reviewers to 'sign off' on studies. Historically, ethics research committees have been viewed as the cautious gatekeepers, ${ }^{26}$ focused on children's status as 'vulnerable'. This is not often the case anymore, with regulators promoting a balanced approach, and valuing children's researchers becoming engaged with developing regulation. An ethically conducted study is recognised as providing 'no or minimal' risk to participants; that is, no greater than everyday life. This series goes on to advise how best to clearly think through and place the arguments for a smooth ethical review of your paediatric study, and the authors are working to develop resources and skills in the same zone for those sat on the other side of the table.

Moving forward can only occur with appropriate funding for research too. We are not delving deep into this aspect of making research happen, but agree with a strategy of planning to improve the quantity and quality of paediatric research, recognising while a minority interest, creating happy and healthy children may have a significant impact on adult health and lifecourse healthcare burden. ${ }^{27}$

\section{THE FUTURE: AGREEING ON HOW TO WORK TOGETHER}

The future will be brighter if we can bring these multiple stakeholder groups, views and competing interests together. Considering how to proactively enter into discussions, and to do this fairly and honestly, we could consider two recent models in health and bioethics-'Democratic deliberation' and 'Accountability for Reasonableness'. ${ }^{28-30}$

Democratic deliberation holds five principles:

1. Evidence informed: Arguments should be supported by appropriate and reasonably accurate factual claims. Cherry picking facts and 'straw man'-based arguments are polemical not honest.

2. Balanced: Arguments should be met by contrary arguments.

3. Conscientious: The participants should be willing to talk and listen, with civility and respect.

4. Substantive: Arguments should be considered sincerely on their merits, not on how they are made or by who is making them.

5. Comprehensive: All points of view held by significant portions of the population should receive attention.

Accountability for Reasonableness, developed by Daniels and Sabin in the setting of managing fair distribution of a limited health resource, adds two further principles propose three elements of fair process:

1. Transparency about the grounds for decisions.

2. Procedures for revising decisions in light of challenges.

Together these approaches lead us to suggest that good research will build on the past, take alternative views and opinions into account, learn from errors and mistakes and work with changing systems to make research safer, more efficient and more relevant. (See online supplementary appendix: Minor Carta.)

\section{THE CONCLUSION}

Engaging and undertaking research with CYP and their families can happen successfully. It takes detailed planning, enthusiasm, the application of resources, thinking, meaningful discussion, people skills, cake, a sprinkle of good luck and lots of effort... but research can occur as part of real life clinical practice. It is unethical for it not to be an integral offering of modern, effective healthcare in the 21 st century. 
Contributors HTD, BP, JP and SRS all designed and debated the series of articles, made editorial comments and assure the validity of the content. HTD drafted this article initially, with comment and involvement from all authors.

Funding This work was not specifically funded by any public or private body. BP is funded by the NIHR Research Trainees Coordinating Centre (grant number 10872).

Competing interests None declared.

Patient consent Not required.

Provenance and peer review Commissioned; externally peer reviewed.

\section{REFERENCES}

1 NIHR Newcastle Biomedical Research Centre. Public urged to take part in clinical research to find new NHS treatments. 2018. https://www.newcastlebrc.nihr.ac.uk/ news/public-urged-to-take-part-in-clinical-research-to-find-new-nhs-treatments/ (accessed Jun 2018).

2 Phillips B. Towards evidence-based medicine for paediatricians. Arch Dis Child 2018;103:1178.2-1178.

3 Shilling V, Williamson PR, Hickey $\mathrm{H}$, et al. Communication about Children's Clinical Trials as Observed and Experienced: Qualitative Study of Parents and Practitioners. 2011. https://doi.org/10.1371/journal.pone.0021604

4 Bedford HE, Elliman DA. MMR vaccine and autism. BMJ 2010;340:c655.

5 Gilbert R, Salanti G, Harden M, et al. Infant sleeping position and the sudden infant death syndrome: systematic review of observational studies and historical review of recommendations from 1940 to 2002. Int J Epidemiol 2005;34:874-87.

6 Terwilliger T, Abdul-Hay M. Acute lymphoblastic leukemia: a comprehensive review and 2017 update. Blood Cancer J 2017:7:e577.

7 Bauchner H. What have we learnt from the Alder Hey affair? BMJ 2001;322:309-10.

8 Hey $E$, Chalmers I. Investigating allegations of research misconduct: the vital need for due process. BMJ 2000;321:752-5.

9 Wit M, Abma T, Loon MK-van, et al. Involving patient research partners has a significant impact on outcomes research: a responsive evaluation of the international OMERACT conferences. BMJOpen 2013;2:e002241.

10 AllTrial.net. http://www.alltrials.net/find-out-more/all-trials/ (accessed Jun 2018).

11 Al-Shahi Salman R, Beller E, Kagan J, et al. Increasing value and reducing waste in biomedical research regulation and management. Lancet 2014;383.

12 EQUATOR Network. Enhancing the QUAlity and Transparency Of health Research. http://www.equator-network.org/ (accessed June 2018).

13 Hobbs FR, Roberts LM. The stern review of the research excellence framework. BMJ 2016:354:i4413
14 Born in Bradford. Born in bradford cohort study 'Gallery'. https://borninbradford.nhs. uk/gallery/. (accessed Oct 2018).

15 Generation R. Generation R Web Homepage. http://generationr.org.uk/ (accessed June 2018).

16 James Lind Alliance. About the James Lind Alliance. http://www.jla.nihr.ac.uk/aboutthe-james-lind-alliance/ (accessed Oct 2018).

17 Brightlight. Youth advisory panel. http://www.brightlightstudy.com/user-involvement/ (accessed Jun 2018).

18 NHR Health Research Authority. Report into public involvement and ethical aspects of research. http://www.hra.nhs.uk/documents/2016/05/impact-public-involvementethical-aspects-research-updated-2016.pdf (accessed Jun 2018).

19 Morgan JE, Phillips B, Stewart LA, et al. Quest for certainty regarding early discharge in paediatric low-risk febrile neutropenia: a multicentre qualitative focus group discussion study involving patients, parents and healthcare professionals in the UK. BMJ Open 2018;8:e020324.

20 de Vries MC, Houtlosser M, Wit JM, et al. Ethical issues at the interface of clinical care and research practice in pediatric oncology: a narrative review of parents' and physicians' experiences. BMC Med Ethics 2011;12:18.

21 Pritchard-Jones K, Dixon-Woods M, Naafs-Wilstra M, et al. Improving recruitment to clinical trials for cancer in childhood. Lancet Oncol 2008;9:392-9.

22 Khadawardi E, Al Hazzani F. Oxygen saturation and outcomes in preterm infants the BOOST II United Kingdom, Australia, and New Zealand Collaborative Groups. J Clin Neonatol 2013;2:73-5.

23 ISRCTN registry. Enteral lactoferrin in neonates [ELfIN Trial]. http://www.isrctn.com/ ISRCTN88261002 (accessed Jun 2018).

24 Lyttle MD, O'Sullivan R, Hartshorn S, et al. Pediatric Emergency Research in the UK and Ireland (PERUKI): developing a collaborative for multicentre research. Arch Dis Child 2014;99:602-3.

25 Jarvis S, Parslow RC, Carragher P, et al. How many children and young people with life-limiting conditions are clinically unstable? A national data linkage study. Arch Dis Child 2017;102:131-8

26 Angell $\mathrm{E}$, Biggs $\mathrm{H}$, Gahleitner $\mathrm{F}$, et al. What do research ethics committees say about applications to conduct research involving children? Arch Dis Child 2010;95:915-7.

27 Belli PC. The economic benefits of investing in child health. HNP discussion paper series. Washington, DC: World Bank, 2003.

28 Fishkin J. When the people speak: Oxford University Press, 2011. ISBN 978-0-19960443-2

29 Fishkin JS, Luskin RC. Experimenting with a democratic ideal: deliberative polling and public opinion. Acta Politica 2005:40:284-98.

30 Daniels N, Sabin J. The ethics of accountability in managed care reform. Health Aff 1998:17:50-64. 